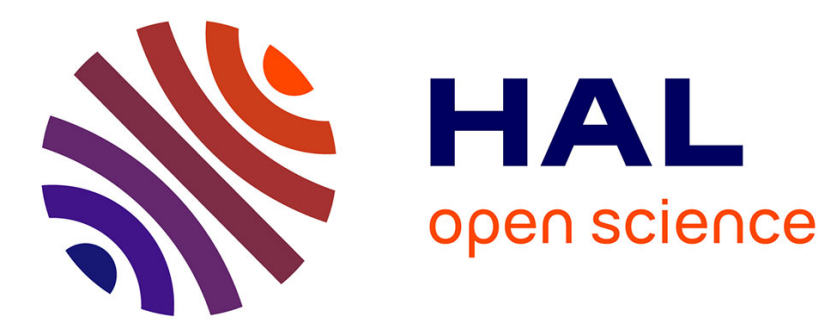

\title{
In-situ creep law determination for modeling Spark Plasma Sintering of TiAl 48-2-2 powder
}

David Martins, Fanny Grumbach, Charles Manière, Pierre Sallot, Katia Mocellin, Michel Bellet, Claude Estournès

\section{- To cite this version:}

David Martins, Fanny Grumbach, Charles Manière, Pierre Sallot, Katia Mocellin, et al.. In-situ creep law determination for modeling Spark Plasma Sintering of TiAl 48-2-2 powder. Intermetallics, 2017, 86, pp.147 - 155. 10.1016/j.intermet.2017.03.006 . hal-01509753

\section{HAL Id: hal-01509753}

https://hal-mines-paristech.archives-ouvertes.fr/hal-01509753

Submitted on 15 Jun 2018

HAL is a multi-disciplinary open access archive for the deposit and dissemination of scientific research documents, whether they are published or not. The documents may come from teaching and research institutions in France or abroad, or from public or private research centers.
L'archive ouverte pluridisciplinaire HAL, est destinée au dépôt et à la diffusion de documents scientifiques de niveau recherche, publiés ou non, émanant des établissements d'enseignement et de recherche français ou étrangers, des laboratoires publics ou privés. 


\title{
In-situ creep law determination for modeling Spark Plasma Sintering of TiAl 48-2-2 powder
}

\author{
David Martins ${ }^{\text {a,b }}$, Fanny Grumbach ${ }^{\text {a }}$, Charles Manière ${ }^{\text {a }}$, Pierre Sallot ${ }^{c}$, \\ Katia Mocellin ${ }^{\mathrm{b}}$, Michel Bellet ${ }^{\mathrm{b}}$, Claude Estournès ${ }^{\mathrm{a},{ }^{*} 1}$
}
(a) Université de Toulouse, CIRMAT CNRS UPS INPT, 118 route de Narbonne, 31062 Toulouse cedex 9, France
(b) Mines ParisTech, PSL - Research University, CEMEF - Centre for Material Forming, CNRS UMR 7635, CS 10207 rue Claude Daunesse 06904 Sophia-Antipolis Cedex, France
(c) Safran CRT Magny-les-Hameaux, France

Keywords: Spark plasma sintering, Ti-48Al-2Cr-2Nb, Creep, Densification parameters, Norton-Green model

\section{$\underline{\text { Abstract }}$}

Spark Plasma Sintering (SPS) is a process which allows powder densification, applying simultaneously a uniaxial external load and pulsed direct current of very high intensity through tools. This process is attracting significant attention, with a tremendous increase of studies in the metal powder densification field. Its growing popularity lies in the very fast heating rate and short cycle time driven by the Joule effect, which limits grain growth. However, this process implements different coupled electrical, thermal and mechanical phenomena. All this makes the process difficult to develop and to apply for routine industrial production, which has motivated the development of numerical simulation tools in order to understand and optimize the process. Up to now, very few models integrating the coupling between heat generation, electric transfer and mechanics have been proposed.

In particular, a numerical predictive model for powder densification requires a good understanding of the mechanical behavior, in our case a viscoplastic compressive law (Abouaf mechanical model). In this article, we will discuss the characterization of the material during densification, focusing on the creep behaviors of dense and porous state materials used to simulate sintering in the Abouaf framework. Validations of the creep law parameters and also of the densification parameters will be presented and subsequently discussed.

\footnotetext{
* Corresponding author: CE: CIRIMAT, 118 route de Narbonne, 31062 Toulouse,

Tel: (+33) 561556109; Fax: (+33) 561556163, E-mail address: estournes@ chimie.ups-tlse.fr
} 


\section{Introduction}

Titanium Aluminide intermetallics are now a reality for structural applications such as aeroengines, replacing nickel based superalloys [1-3]. The combination of a relatively high yield strength at high temperatures with good creep resistance, excellent resistance to oxidation / corrosion and their low density $(3.9-4.1 \mathrm{~g} / \mathrm{cc}$ ) have contributed to their introduction on aeroengines' low pressure turbine blades or turbochargers in the automotive industry [4-5]. Several processes are available to produce TiAl alloys, such as classical fusion processes (Vacuum Arc Remelting (VAR)), hot working techniques [1-3,6] and casting [7]. The first step involves mixing starting raw materials and melting them in VAR. Then, shaping is achieved by the casting technique using centrifugation or gravity depending on the complexity of the parts to produce. However, chemical homogeneity as well as microstructure control could be an issue when using casting, and can imply dispersions of mechanical properties. Powder Metallurgy is a good alternative to deal with part of these drawbacks and is worth studying; SPS can be compared to Hot Pressing (HP) but it is considered as a nonconventional densification process. Like in HP, a uniaxial external load is applied to the powder, which leads to more rapid densification compared to free sintering [8]. The major difference between the two techniques lies in the fact that in SPS the heating source is provided by the Joule effect, produced by a pulsed current applied through the tools. Depending on their relative electrical conductivity, heat is generated in the sample itself (i.e. if the sample is more conductive than the tool) or in the tools [9-10]. Heating rates and external applied pressures can be as high as $1000 \mathrm{~K} / \mathrm{min}$ and $150 \mathrm{MPa}$ respectively, depending on the tools. This method can densify a large range of materials such as polymers, metals, ceramics and their composites. The major advantage of this process is the control of the microstructure generated and its homogeneity in the bulk after sintering [11]. Densification rates as well as microstructure evolutions are closely linked to process parameters such as temperature and pressure distribution within the whole volume, and notably when considering complex-shaped parts. Thus, finite element modeling (FEM) of the whole process is a very efficient way to further optimize tooling design and SPS parameters.

Two main phenomena are usually modeled in SPS: heat generation by the Joule effect and densification. The electro-thermal component of the process can be modeled by a simple resistive approach with very good accuracy [10,12-13]. At the different interfaces between the tools and the powder, electrical and thermal contacts have to be considered as they greatly affect the temperature field [9,14-18]. 
Considering densification under an external applied pressure field, viscoplastic laws are often used to describe the sintering process. Famous expressions developed by Abouaf [19], Olevsky [20-21] or Camclay [1] are gateways between dense and porous mechanic fields. To simulate densification using such approaches, identification of creep law parameters for both dense and porous material is crucial. These data are usually very time-consuming to acquire and require many interrupted experiments at different temperatures and pressures on dense and porous samples. These parameters are often determined using HIP (Hot Isostatic Pressure) cycles [2,19,22] which require several hours of handling [2] and thus restrict the identification of such parameters to coarse microstructures.

Being able to run such experiments using SPS is very attractive for several reasons. The short processing time associated with SPS allows an identification of the parameters on controlled microstructures. It opens a way to take into account, in simulations, the impact of microstructure evolution on sintering. A growing number of authors use reverse analysis to determine the powder compaction parameters from SPS tests [19-20,23]. Manière et al [3] have developed an original methodology, based on the work of Geindreau et al [4], to determine by a set of experiences, the parameters of the creep law for TA6V processed using SPS in-situ. This methodology will be applied in the present study to TiAl 48-2-2.

\section{The constitutive model: Norton-Green compressible viscoplasticity}

The densification of a metal powder during electrically activated sintering results from different physical phenomena: the plastic deformation of powder particles $\left(\dot{\boldsymbol{\varepsilon}}^{p l}\right)$, the mass transport between particles by diffusion under load $\left(\dot{\boldsymbol{\varepsilon}}^{d l}\right)$, the mass transport between particles by electro-migration $\left(\dot{\varepsilon}^{e m}\right)$ and the mass transport due to surface tension $\left(\dot{\boldsymbol{\varepsilon}}^{\text {st }}\right)$ [24]. As a consequence, the global deformation rate of the powder material, considered as a compressible continuum, can be expressed as the sum of the five contributions:

$$
\dot{\boldsymbol{\varepsilon}}=\dot{\boldsymbol{\varepsilon}}^{p l}+\dot{\boldsymbol{\varepsilon}}^{d l}+\dot{\boldsymbol{\varepsilon}}^{e m}+\dot{\boldsymbol{\varepsilon}}^{s t}+\dot{\boldsymbol{\varepsilon}}^{t h}
$$

Where $\left(\dot{\boldsymbol{\varepsilon}}^{\text {th }}\right)$ is the thermal dilatation.

At high temperature, which is the domain of interest for effective densification in SPS conditions, it is assumed that elastic effects can be neglected. Moreover, and as a first approximation, the respective contributions of electro-migration and transport by diffusion are neglected. Equation (1) reduces then to:

$$
\dot{\boldsymbol{\varepsilon}}=\dot{\boldsymbol{\varepsilon}}^{v p}+\dot{\boldsymbol{\varepsilon}}^{t h}
$$


Where $\dot{\boldsymbol{\varepsilon}}^{p l}$ is replaced by $\dot{\boldsymbol{\varepsilon}}^{v p}$ assuming that particles deformation is purely viscoplastic at high temperature.

The constitutive model of the powder material should provide a relationship between the Cauchy stress tensor $\boldsymbol{\sigma}$ and the viscoplastic part of the strain-rate tensor $\left(\dot{\boldsymbol{\varepsilon}}^{v p}\right)$. The selected constitutive model is the one proposed by Shima and Oyane [25], which consists of an extension of the viscoplastic power law usually used for high temperature creep of metallic alloys in the dense state. The two next paragraphs contain a brief reminder of this power law and a description of its extension to porous (not dense) materials.

\subsection{Viscoplastic power law for creep in the dense state}

Metallic alloys generally obey a viscoplastic power law when deformed at high temperature:

$$
\dot{\bar{\varepsilon}}=A(T) \bar{\sigma}^{n}
$$

Where $\bar{\sigma}=\sqrt{\frac{3}{2} \mathbf{s}: \mathbf{s}}$ denotes the von Mises equivalent stress $\mathbf{s}=\boldsymbol{\sigma}-\frac{1}{3}(\operatorname{tr} \mathbf{\sigma}) \mathbf{I}$ the deviatoric stress tensor; I the identity tensor) and $\dot{\bar{\varepsilon}}=\sqrt{\frac{2}{3} \dot{\boldsymbol{\varepsilon}}^{v p}: \dot{\boldsymbol{\varepsilon}}^{v p}}$ is the generalized strain rate.

The viscoplastic behavior is characterized by the temperature dependent function $A$ and by $n$, a constant coefficient. Function $A$ is assumed to follow an Arrhenius law:

$$
A(T)=A_{0} e^{\left(\frac{-Q}{R T}\right)}
$$

Where $A_{0}$ is a pre-exponential term, $Q$ the activation energy (J.mol $\left.{ }^{-1}\right), R$ the universal gas constant and $T$ the absolute temperature $(K)$.

Equation (3) shows that the generalized strain-rate derives from a stress potential:

$$
\psi(\bar{\sigma}, T)=\frac{A(T)}{n+1} \bar{\sigma}^{n+1} \quad \dot{\bar{\varepsilon}}=\frac{\partial \psi}{\partial \bar{\sigma}}
$$

The tensor constitutive equation can then be obtained by the normality rule:

Leading to:

$$
\dot{\boldsymbol{\varepsilon}}^{v p}=\frac{\partial \psi}{\partial \boldsymbol{\sigma}}=\frac{\partial \psi}{\partial \bar{\sigma}} \frac{\partial \bar{\sigma}}{\partial \boldsymbol{\sigma}}
$$

$$
\dot{\boldsymbol{\varepsilon}}^{v p}=\frac{3}{2} A(T) \bar{\sigma}^{n-1} \mathbf{s}
$$




\subsection{Extension to the case of a porous metallic alloy}

This extension relies first on the definition of the equivalent stress, as proposed by Green $[5,26]:$

$$
\bar{\sigma}=\left[\frac{3 c}{2} \mathbf{s}: \mathbf{s}+f(\operatorname{tr} \boldsymbol{\sigma})^{2}\right]^{1 / 2}
$$

With $c$ and f two decreasing functions of the relative density $\rho_{r}$.

When densification tends to be completed $\left(\rho_{r} \rightarrow 1\right.$ ), the limit values of $c$ and $f$ should be 1 and 0 , respectively, in order to retrieve the standard von Mises expression for $\bar{\sigma}$. Different expressions for $c$ and $f$ functions can be found in the literature ([4,6,27]). On the interval $\left\lfloor\rho_{r, c r i t} ; 1\right]$ for the relative density, there are the general expressions:

$$
c=1+\alpha f \quad f=K_{f}\left(\frac{1-\rho_{r}}{\rho_{r}-\rho_{r, \text { crit }}}\right)^{\gamma}
$$

With $\alpha, K_{f}, \gamma, \rho_{r, \text { crit }}$ material parameters.

In the equation (10), $\alpha, K_{f}, \gamma$ are dimensionless with no physical meaning, whereas $\rho_{r, c r i t}$ can be considered as the green relative density .

As proposed by to Shima and Oyane [25] and by Abouaf [19], for a porous media, the tensor form of the constitutive equation is written in the same form as for the dense material, Eq.(6) and using the same potential function $\psi$ as in the dense state, but with the modified expression of the generalized stress (Eq. (8)). We obtain:

$$
\dot{\boldsymbol{\varepsilon}}^{v p}=\frac{\partial \psi}{\partial \bar{\sigma}} \frac{1}{\bar{\sigma}}\left(\frac{3 c}{2} \mathbf{s}+f(\operatorname{tr} \boldsymbol{\sigma}) \mathbf{I}\right)
$$

Taking the deviatoric part and the trace of this expression, we have:

$$
\mathbf{S}=\frac{2 \bar{\sigma}}{3 c}\left(\frac{\partial \psi}{\partial \bar{\sigma}}\right)^{-1} \operatorname{dev}\left(\dot{\boldsymbol{\varepsilon}}^{v p}\right) \quad \operatorname{tr}(\boldsymbol{\sigma})=\frac{\bar{\sigma}}{3 f}\left(\frac{\partial \psi}{\partial \bar{\sigma}}\right)^{-1} \operatorname{tr}\left(\dot{\boldsymbol{\varepsilon}}^{v p}\right)
$$

Where dev stands for the deviatoric part. Injecting those two expressions in the equation for the equivalent stress, we obtain:

$$
\frac{\partial \psi}{\partial \bar{\sigma}}=\left(\frac{2}{3 c} \operatorname{dev}\left(\dot{\boldsymbol{\varepsilon}}^{v p}\right): \operatorname{dev}\left(\dot{\boldsymbol{\varepsilon}}^{v p}\right)+\frac{1}{9 f}\left(\operatorname{tr} \dot{\boldsymbol{\varepsilon}}^{v p}\right)^{2}\right)^{\frac{1}{2}}
$$


This suggests that the expression on the right hand side should be used for the equivalent or generalized strain rate in the context of a porous material. Thus, the power of deformation per unit of volume may be expressed as

$$
\dot{w}=\boldsymbol{\sigma}: \dot{\boldsymbol{\varepsilon}}^{v p}=\frac{\partial \psi}{\partial \bar{\sigma}} \frac{1}{\bar{\sigma}}\left(\frac{3 c}{2} \mathbf{s}: \mathbf{s}+f(\operatorname{tr} \boldsymbol{\sigma})^{2}\right)=\bar{\sigma} \dot{\bar{\varepsilon}}
$$

Finally, the viscoplastic compressible equation takes the following form:

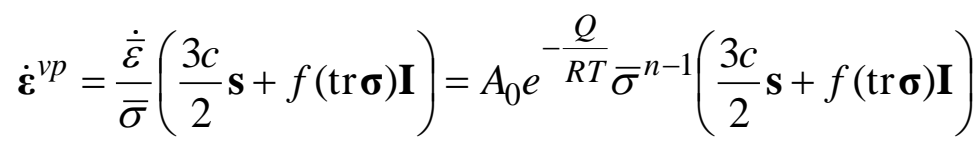

Different material parameters must be identified for this constitutive equation. Parameters $A_{0}$, $Q$ and $n$ are associated with the intrinsic viscoplastic behavior of the metal that constitutes the powder particles. Those three parameters can be identified with tests performed on a fully densified specimen, provided that its microstructure is representative of the powder particles, especially in terms of metallurgical grain size. Conversely, the functions $c$ and $f$ describe the impact of the relative density $\rho_{r}$ on the mechanical deformation of the powder material. They are assumed to depend on $\rho_{r}$ exclusively. For this reason, they can be identified by performing different compaction tests conducted on porous samples with different relative densities.

Before defining precisely an identification strategy, we will examine what the relationships are between stress and strain rate for two specific cases which will be used afterwards: free compression and confined compression.

2. Model equations in different configurations and definition of a strategy for parameters identification

\subsection{Equations for free compression in the dense state}

Free compression along the vertical direction $z$ is supposed to be induced by a constant force $F$, applied to a plain cylindrical specimen, which is maintained at a constant temperature. Assuming a perfect lubrication, the stress state is found to be uniaxial and uniform through the specimen. In a coordinate system $(r, \theta, z)$, the stress tensor writes:

$$
\boldsymbol{\sigma}=\left[\begin{array}{ccc}
0 & 0 & 0 \\
0 & 0 & 0 \\
0 & 0 & \sigma_{z z}
\end{array}\right]
$$

As the temperature is constant, Eq. (2) reduces to $\dot{\boldsymbol{\varepsilon}}=\dot{\boldsymbol{\varepsilon}}^{v p}$, and we have, from Eq. (7): 


$$
\dot{\varepsilon}_{z z}=-A\left|\sigma_{z z}\right|^{n}=-A_{0} e^{-\frac{Q}{R T}}\left|\sigma_{z z}\right|^{n}
$$

\subsection{Equations for free compression in the porous state}

A similar situation, but for a compressible porous material, will now be considered. The stress tensor is equally uniaxial. From Eq. (8) we have:

$$
\bar{\sigma}=\sqrt{c+f}\left|\sigma_{z z}\right|
$$

Applying the flow rule, Eq. (15), we obtain:

$$
\dot{\varepsilon}_{z z}=-A(T)(c+f)^{\frac{n+1}{2}}\left|\sigma_{z z}\right|^{n}
$$

\subsection{Equations for confined compression in the porous state}

Suppose now that the compression is operated with a tooling which restrains the specimen from any diameter variation. Still assuming a uniform strain rate, we have:

$$
\dot{\boldsymbol{\varepsilon}}=\left[\begin{array}{ccc}
0 & 0 & 0 \\
0 & 0 & 0 \\
0 & 0 & \dot{\varepsilon}_{z z}
\end{array}\right]
$$

From Eq. (13), the equivalent strain rate writes:

$$
\dot{\bar{\varepsilon}}=\frac{\left|\dot{\varepsilon}_{z z}\right|}{3} \sqrt{\frac{4}{c}+\frac{1}{f}}
$$

Applying Eq. (12), we obtain:

$$
s_{z z}=\frac{4}{9 c} \frac{\bar{\sigma}}{\dot{\bar{\varepsilon}}} \dot{\varepsilon}_{z z} \quad \text { and } \quad \operatorname{tr}(\boldsymbol{\sigma})=\frac{1}{3 f} \frac{\bar{\sigma}}{\dot{\bar{\varepsilon}}} \dot{\varepsilon}_{z z}
$$

This leads to:

$$
\begin{aligned}
\sigma_{z z} & =S_{z z}+\frac{1}{3} \operatorname{tr} \boldsymbol{\sigma}=\frac{\bar{\sigma}}{9 \dot{\bar{\varepsilon}}}\left(\frac{4}{c}+\frac{1}{f}\right) \dot{\varepsilon}_{z z}=\frac{1}{9}\left(\frac{1}{A}\right)^{\frac{1}{n}} \dot{\bar{\varepsilon}}^{\frac{1}{n}-1}\left(\frac{4}{c}+\frac{1}{f}\right) \dot{\varepsilon}_{z z} \\
& =-A(T)^{-\frac{1}{n}}\left(\frac{1}{3}\right)^{\frac{1}{n}+1}\left(\frac{4}{c}+\frac{1}{f}\right)^{\frac{1}{2}\left(\frac{1}{n}+1\right)}\left|\dot{\varepsilon}_{z z}\right|^{\frac{1}{n}}
\end{aligned}
$$


Or, equivalently, to:

$$
\dot{\varepsilon}_{z z}=-3^{n+1} A(T)\left(\frac{4}{c}+\frac{1}{f}\right)^{-\frac{1}{2}(1+n)}\left|\sigma_{z z}\right|^{n}
$$

\subsection{Definition of the identification strategy}

The usual strategy for the identification of the different parameters combines different tests [3]. First, uniaxial compression tests are conducted on the material in the dense state, at different temperatures, from which $A_{0}, Q$ and $n$ can be determined. Second, isostatic pressing tests are performed in the non-dense state on specimens with different relative densities. Such tests can provide a direct determination of the function $f\left(\rho_{r}\right)$. Finally, complementary tests, still performed in the non-dense state and for different relative densities, are used to determine a combination of $c$ and $f$, from which the function $c\left(\rho_{r}\right)$ can be determined.

In the framework of the present study, a similar strategy for the identification of the full set of material parameters has been used. The difference lies on the fact that it is based on the sole use of tests which could be carried out in the SPS pressing device. The different testing conditions are the following ones:

- uniaxial free compression at different temperatures of cylindrical specimens made of densified powder. The tests are conducted in a creep mode, by prescribing the axial force;

- uniaxial free compression of non-dense cylindrical specimen, at uniform temperature, and for different values of imposed axial force;

- confined compression of non-dense cylindrical specimen in a die, at uniform temperature, and for different values of imposed axial force.

Like in the usual strategy developed in [3], the dense state tests allow the determination of parameters $A_{0}, Q$ and $n$. The difference lies in the fact that it is now a combined analysis of the results of the other tests (free and confined uniaxial compressions) that will lead to the determination of $c$ and $f$ functions. The experimental tests, together with their rough results, are presented in the next section. 


\section{Experimental}

All the SPS experiments (i.e. : densifications and in-situ creep tests) were carried out on a Dr. Sinter 2080 device of the Plateforme Nationale CNRS de Frittage Flash located at the Université Toulouse III Paul Sabatier at Toulouse.

The TiAl composition involved in this study is the Ti-48Al-2Nb-2Cr (at\%) alloy, currently used on GE90 or LEAP engines. The powder was supplied by Safran Tech and developed by General Electrics. The main chemical species are titanium and aluminum, with chromium and niobium as alloying elements.

The shape and the grain size distribution of the powder were controlled by Scanning Electron Microscope (SEM) characterizations (Figure 1).
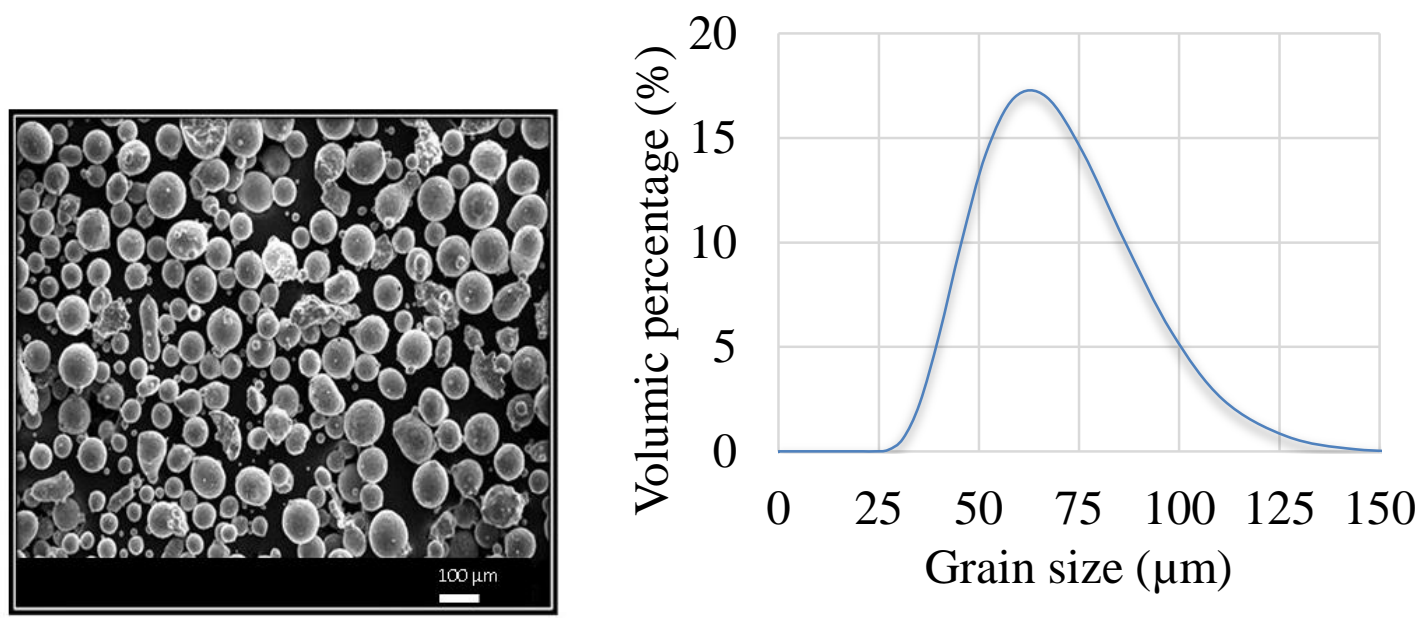

Figure 1 : Ti-48Al-2Nb-2Cr powder under the Scanning Electron Microscope (SEM) (a), Grain size curve distribution obtained by laser granulometry analysis (b)

Concerning the morphology of the powder, grains are mostly spherical. Some heterogeneities, such as elongated grains or satellites are noticeable on Figure 1-a. We also note the presence of several grain size particules (Figure 1-b) between 30 and $144 \mu \mathrm{m}$. Laser granulometry analysis of the powder revealed that $10 \%$ of the volume of the powder had a size less than $46,6 \mu \mathrm{m}$. The $50 \%$ of the volume of the powder has a size smaller than $67,6 \mu \mathrm{m}$. For large particles, $10 \%$ of the volume studied is larger than $97,9 \mu \mathrm{m}$ (Table 1)

The characteristics of the powder are given on Table 1 


\begin{tabular}{|c|c|c|c|}
\hline \multicolumn{2}{|c|}{ Grain size $(\mu \mathrm{m})$} & \multicolumn{2}{c|}{$\begin{array}{c}\text { Interstitial } \\
\text { contamination (wppm) }\end{array}$} \\
\hline D10 & 46,6 & $\mathrm{C}$ & 76 \\
\hline D50 & 67,6 & $\mathrm{O}$ & 760 \\
\hline D90 & 97,9 & $\mathrm{~N}$ & $<5$ \\
\hline
\end{tabular}

Table 1 : Grain size distribution and interstitial contamination

\subsection{Uniaxial free compression tests on full dense and porous material}

In both cases, samples were obtained by SPS compaction in graphite molds. They are all 8mm in diameter. Dense specimens are $10 \mathrm{~mm}$ in height whereas the porous ones are taller (Table 2). Porosity-controlled samples were produced using seven interrupted SPS sintering cycles performed under vacuum (Table 2). The heating rate was $100 \mathrm{~K} / \mathrm{min}$ and the pressure applied was $50 \mathrm{MPa}$ without any dwell. With this SPS cycle and for each of the seven specimens, the only difference was the maximum temperature reached (Table 2)

\begin{tabular}{|c|c|c|c|c|c|c|c|}
\hline $\begin{array}{c}\text { Temperature } \\
\text { max }\left({ }^{\circ} \mathrm{C}\right)\end{array}$ & 935 & 975 & 995 & 1005 & 1035 & 1100 & 1200 \\
\hline $\begin{array}{c}\text { Obtained } \\
\text { relative density }\end{array}$ & 0,77 & 0,88 & 0,91 & 0,93 & 0,96 & 0,99 & $\begin{array}{c}1 \text { (dense } \\
\text { samples })\end{array}$ \\
\hline $\begin{array}{c}\text { Obtained height } \\
(\mathrm{mm})\end{array}$ & 12,98 & 11,49 & 10,98 & 10,87 & 10,41 & 10,1 & 10 \\
\hline
\end{tabular}

Table 2 : Sintering conditions to obtain samples for uniaxial free compression tests

The average relative density was estimated from the geometrical method. For samples exhibiting higher relative density than 0,95 verification by Archimedes' method was also performed.

Uniaxial free compression tests were performed in a graphite mold, $20 \mathrm{~mm}$ in diameter, used to avoid any contact between the creeping sample and the mold. During the tests the temperature of the sample and the load applied to the punches, as well as the lower punch displacement were continuously recorded.

All tests were performed in the SPS using indirect heating, i.e. the Joule effect was induced in the graphite tools surrounding the samples which were subsequently heated by radiation. To achieve indirect heating, graphite sheets (papyex) of $10 \mathrm{~mm}$ diameter with a thickness of 0.2 $\mathrm{mm}$ were coated with boron nitride on each side. They were placed between the sample and the punches for electrical insulation, in order to avoid direct Joule heating of the sample. The circular surfaces of the pistons in contact with these graphite sheets were also coated with boron nitride. Another graphite sheet was placed between the punches and the mold (Figure 2a). Boron nitride is also a very good lubricant which avoids the barrel effect of the sample. All 
this allows a homogeneous distribution of the temperature during the experiment [3]. First, according to the methodology developed by Maniere et al., a partially open mold was used (Figure 2-b) to run the tests, but it was found that the temperature was not homogeneous in the sample (temperature given by thermocouple $\mathrm{n}^{\circ} 2$ was higher than that given by $\mathrm{n}^{\circ} 1$ ). A closed mold was finally used (Figure 2-c) and tests indicated that the temperature on thermocouple $\mathrm{n}^{\circ} 1$ and 2 was the same. All the following free compression tests were performed with this closed mold.

A thermocouple was positioned at mid height on the samples surface (thermocouple $n^{\circ} 2$ Figure 2-c) to allow the control of temperature.

a)
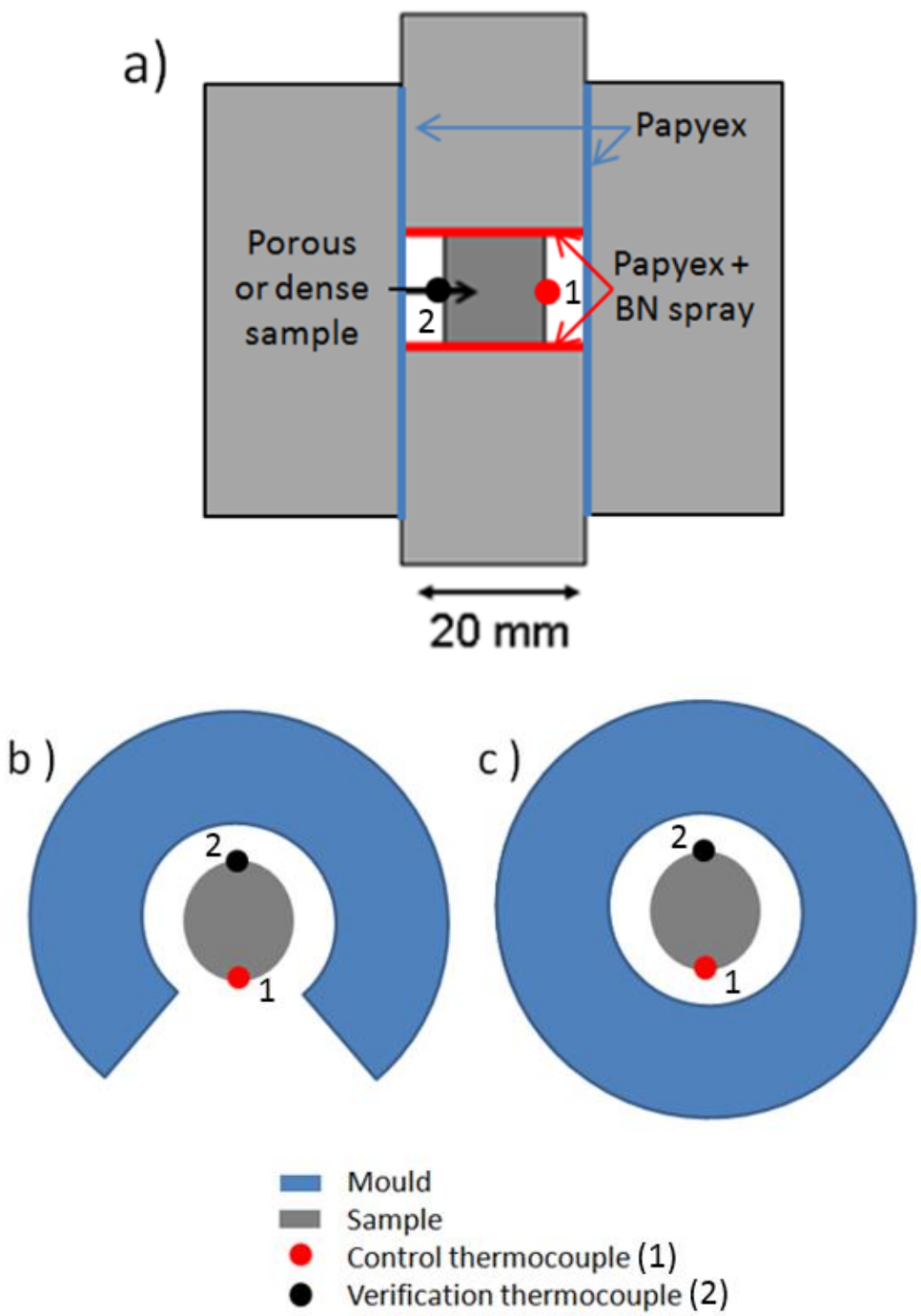

Figure 2 : Experimental configurations in situ in the SPS for (a), uniaxial free compression for a dense or porous material, (b) partially open mold and (c) closed mold with thermocouple positions. 


\subsection{Confined compression on porous material}

Isothermal confined compression tests were carried out for various levels of applied pressure until complete densification was reached. The temperature was controlled with thermocouple $\mathrm{n}^{\circ} 2$ (Figure 3). To assess the real powder temperature during densification, the SPS cycle was reproduced a second time with a sacrificial thermocouple ( ${ }^{\circ} 1$ Figure 3 ) introduced in the middle of the powder. Due to the thermal gradient between the powder and the tools, the real compression temperature was then determined. The experimental setup is schematized (Figure 3). Between graphite (pistons and mold) and powder, a sheet of papyex graphite was used (blue lines in the Figure 3). This prevents powder from reacting with the mold and avoids any friction between the powder and the mold [28].

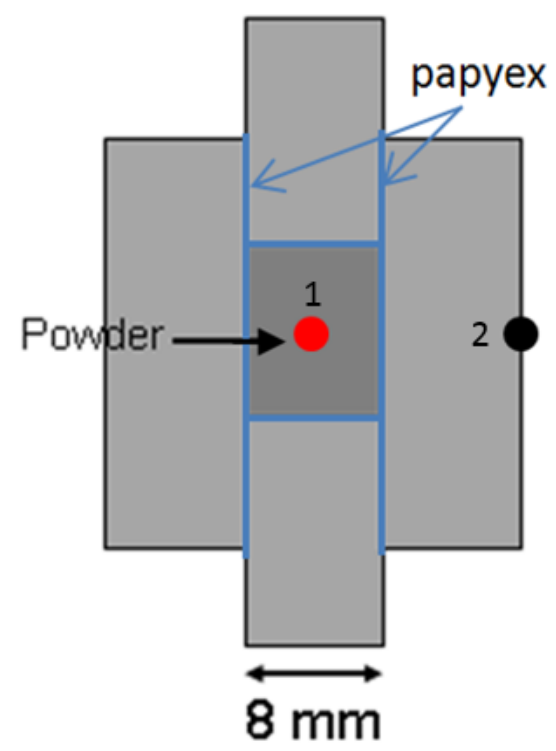

Figure 3 : Powder compaction test in the SPS

\section{Creep parameters determination}

\subsection{Hypothesis and method}

The uniaxial free compression test for dense samples was conducted under uniform and stable thermal conditions. The value of the parameter $A$ is then constant during the whole experiment.

We get from the Equation (17):

$$
\ln \left|\dot{\varepsilon}_{z z}\right|=\ln A(T)+n \ln \left|\sigma_{z z}\right|
$$

The strain rate was computed using the time evolution of the lower punch displacement $(h)$ as follows: 


$$
\dot{\varepsilon}_{z z}=\left(\frac{d\left(\ln \left(\frac{h}{h_{0}}\right)\right)}{d t}\right)
$$

Where $h_{0}$ and $h$ are the height at the initial stage and at a given time respectively.

The load recorded by the SPS being the load which must be converted to stress using the section of the specimen. Considering a fully dense sample, its volume is constant and the section is deduced from:

$$
S h=S_{0} h_{0} \quad \sigma_{z z}=-\frac{F}{S}=-\frac{F}{\pi R_{0}^{2}} \frac{h}{h_{0}}
$$

Where $S$ and $S_{0}$ are the value of the section at a given time and initial. $R_{0}$ is the initial radius of the sample.

\subsection{Identification of creep parameters}

First, 3 specimens were fully densified in the SPS at $1200{ }^{\circ} \mathrm{C}\left(50 \mathrm{MPa}, 3^{\prime}\right)$ and subsequently cooled to room temperature after completion of the experiments. Creep tests were performed on the temperature range achievable for TiAl compression by SPS, i.e. $\left(925-975 \mathrm{C}^{\circ}\right)$. Below this temperature range, the load to be applied in order to have some significant creep displacement is too high and reaches graphite tool limits 7,53 kN (ie $150 \mathrm{MPa}$ ).

When creep tests were performed at higher temperatures, the displacement of the pistons was too rapid. The section evolves too much for each step so the constraint is not constant. The data recorded during a creep test of a full dense sample at $975{ }^{\circ} \mathrm{C}$ is shown in the Figure 4 


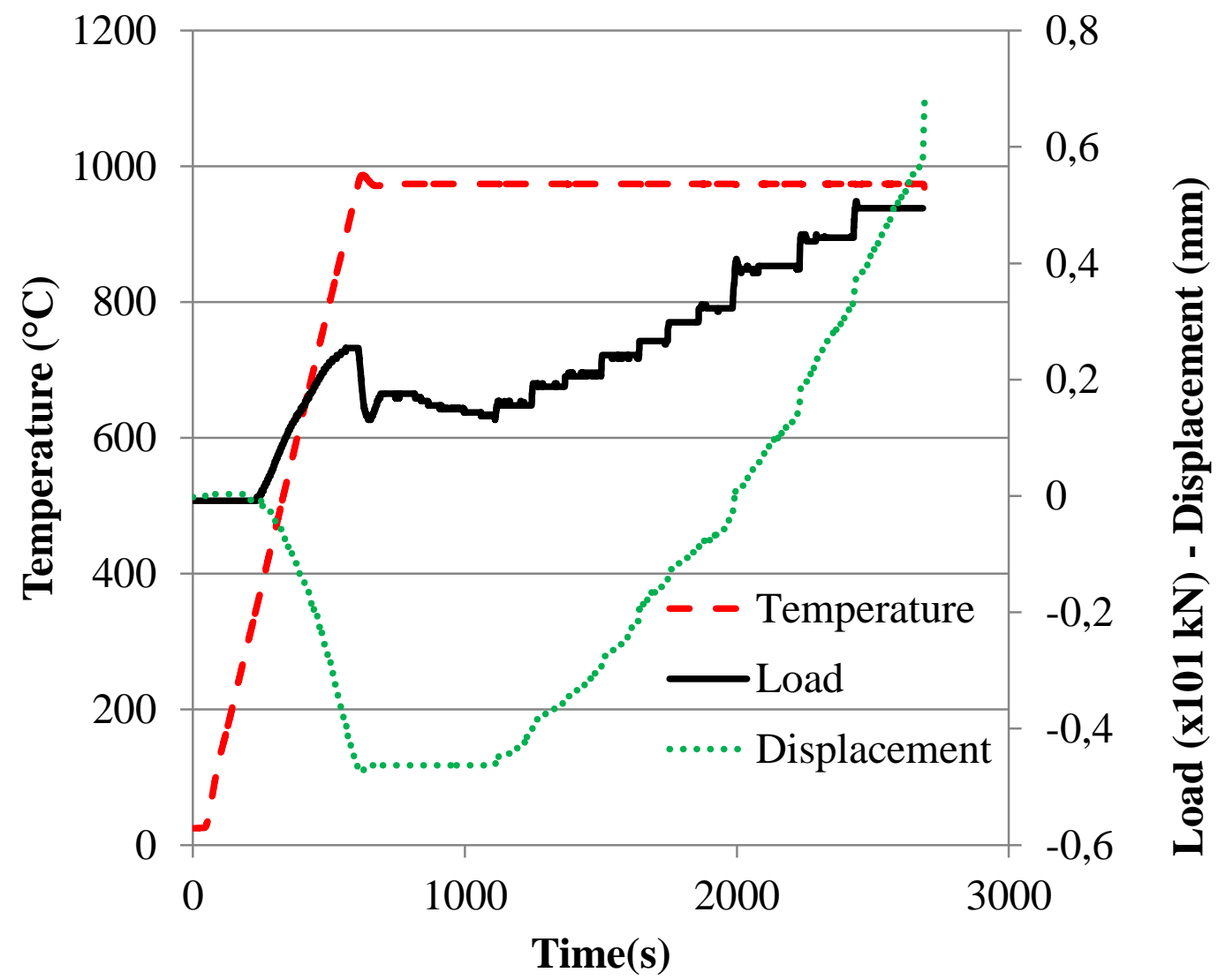

Figure 4 : Load, displacement and temperature evolution during a free compression test in- situ in the SPS at $975^{\circ} \mathrm{C}$

Figure 4 three different curves as a function of time are plotted. In red, the temperature of the sample (measured with the control thermocouple), in black the different load stages applied when the isothermal state is reached and stabilized, and then in green the evolution of the displacement of the lower punch. To ensure a proper contact between the samples and the tools, a very low load was imposed during heating. It should be noted that the evolution of the load before reaching the isothermal step results from the thermal expansion of the different part constituting the SPS column. Indeed, at the very beginning of the process, a contact force is applied and the punch height is recorded. During heating the tools and the specimen expand and so in order to keep this punch position the value of the force increases.

After each creep test, all the samples were examined to verify that their cylindrical shape was retained and thus, if uniaxial conditions were respected. In Figure 5 are summarized all the experimental values of $\ln \dot{\bar{\varepsilon}}$ obtained for different applied stress. 

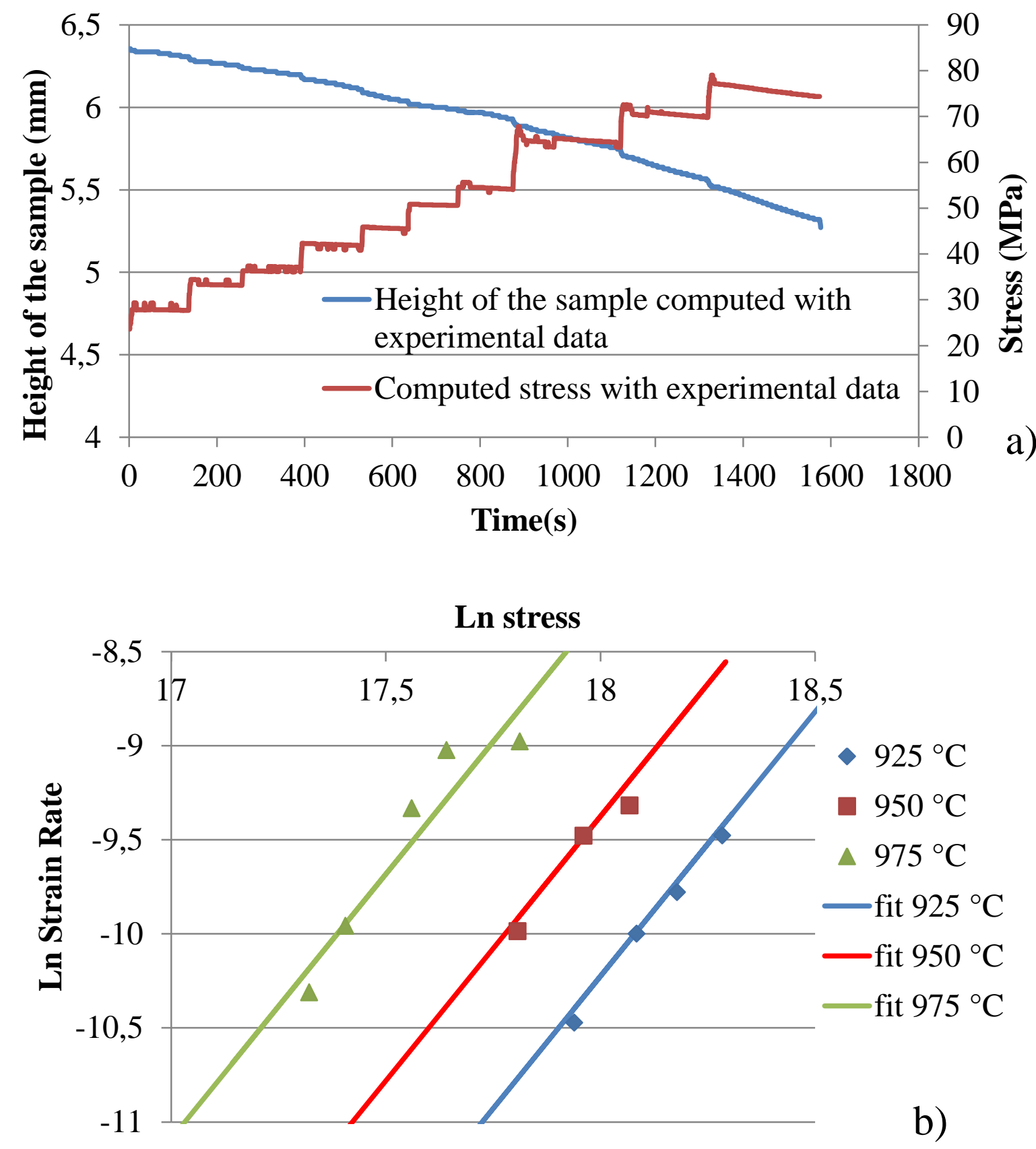

Figure 5 : Time evolution of the height of the sample and the applied stress at $975^{\circ} \mathrm{C}$ (a) and evolution of $\ln (\dot{\bar{\varepsilon}})$ against $\ln (\bar{\sigma})$ (b) for the 3 different creep tests performed on the full dense material in-situ SPS

Figure 5-a, presents the time evolution of the axial stress and the height of the sample during a free compression test at $975{ }^{\circ} \mathrm{C}$. The load applied for each of the 10 steps was constant. As it can be seen from Figure 5-a (red curve) for the first 7 steps, the stresses computed are constant with time. For the other ones, the stresses decreased during each step. So only this 7 step can be used for the determination of the creep parameters. This phenomenon can be 
explained by the rapid and strong increase of the specimen sections due to large creep rates. In these cases, the stress cannot be assigned with an average value and thus this part of the curve is not being used. Finally, 2 other steps remain noisy, which could generate some errors for the creep parameters identification.

As a consequence, at $975^{\circ} \mathrm{C}$, only 5 steps will be considered from the 10 observed in Figure $5-a$.

Figure 5-b represents the evolution of $\ln (\dot{\bar{\varepsilon}})$ as a function of $\ln (\bar{\sigma})$ for valid tests at three temperatures : 925,950 and $975{ }^{\circ} \mathrm{C}$ with the load ranges respectively of $[2,78-5,10 \mathrm{kN}]$, [2,60-5,25 kN] and [1,55-4,94 kN].

Using a linear regression method on these data, creep parameter values were determined as: $A_{0}=3,1410{ }^{8} \mathrm{MPa}^{-n} \mathrm{~s}^{-1}, Q=414163 \mathrm{~J} . \mathrm{mol}^{-1}$ and $n=2,81$.

\subsection{Validation of creep parameters}

To validate the creep law established, the free compression test, performed at $975{ }^{\circ} \mathrm{C}$, was simulated with the finite element software FORGE® using the parameters $A_{0}, n$ and $Q$ determined previously. The imposed boundaries conditions and the initial geometry of the sample at the different force applied were extracted from experimental creep data. Figure 6 compares the height evolution of the sample during the creep test as recorded experimentally and as calculated with FORGE®. The stresses simulated is plotted in the figure 6 too. Considering the time and load range explored, the simulated final displacement is in firm agreement with the experimental one. The same comparison was made for tests performed at 925 and $950{ }^{\circ} \mathrm{C}$, also with strong agreement. Thus, it validates the determination of creep parameters and the identification strategy described in section 4.2. 
- Height of the sample computed with experimental data

- Height of the sample computed wit Forge(r)

-Computed stress with Forge(r)

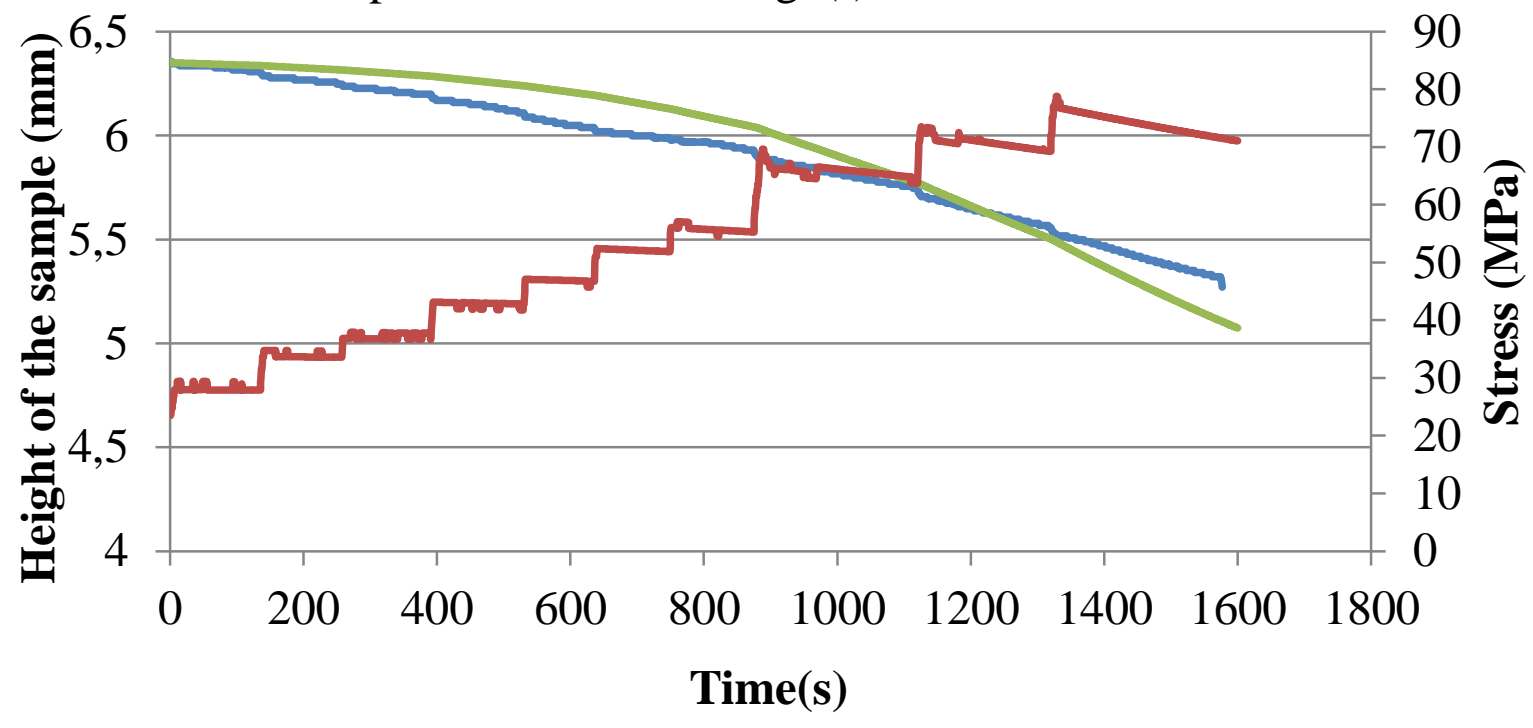

Figure 6 : Simulated and experimental creep test performed on a full dense sample at $975{ }^{\circ} \mathrm{C}$

\section{Identification of functions $c$ and $f$}

To further model material densification, the 2 functions $c\left(\rho_{r}\right)$ and $f\left(\rho_{r}\right)$ must be determined using two kind of tests performed on non-dense specimens: uniaxial free compression and confined compression.

For a given relative density $\rho_{r}$, the values of $c$ and $f$ functions can be determined by the resolution of the equation for the uniaxial compression and for the confined compression, combined in the following system (28). The sum $c+f$ is obtained from porous creep tests (with configuration described in Figure: $2 c$ ) and the sum $4 / c+1 / f$ from non-dense confined compression compaction tests (with configuration described in Figure 3). 


$$
\left\{\begin{array}{c}
c+f=\left(\frac{\left|\dot{\varepsilon}_{z z}\right|}{A\left|\sigma_{z z}\right|^{n}}\right)^{\frac{2}{n+1}} \\
\frac{4}{c}+\frac{1}{f}=\left(9 A^{\frac{1}{n}}\left|\sigma_{z z}\right|\left|\dot{\varepsilon}_{z z}\right|^{-\frac{1}{n}}\left(\frac{1}{3}\right)^{\frac{n-1}{n}}\right)^{\frac{2 n}{n+1}}
\end{array}\right.
$$

Provided that $A_{0}, Q$ and $n$ are known, the resolution of the system (28) gives a unique solution. For $c+f$, the creep test is performed at constant temperature, thus $A$ is directly computed using the earlier coefficients. During the experiment, the stress $\sigma_{z z}$ is computed using eq. (27). After each free compression test, the diameter and the relative density of the sample were measured and no significant changes were observed. Therefore, the necks keep the same geometry all the time meaning that no mass transfer takes place.

$\dot{\varepsilon}_{\text {zz }}$ was calculated using the displacement of the lower punch and finally, the value $c+f$ was calculated and summarized in Figure 8-a (blue dots). Contrary to the creep test on dense material, a single load dwell was applied to porous samples. The explanation lies in the fact that for porous material, volume conservation hypothesis is no longer valid and the actuation of specimen section through eq. (27) is no longer possible.

The free compression test conditions on porous material are summarized in Table 3:

\begin{tabular}{|c|c|c|c|c|c|c|c|}
\hline Relative density & 0,77 & 0,88 & 0,91 & 0,93 & 0,96 & 0,99 & 1,00 \\
\hline $\begin{array}{c}\text { Temperature } \\
\left({ }^{\circ} \mathrm{C}\right)\end{array}$ & 775 & 825 & 850 & 850 & 875 & 950 & 950 \\
\hline Load $(\mathrm{kN})$ & 4,2 & 4,6 & 4,95 & 4,85 & 4,2 & 4,37 & 4,43 \\
\hline
\end{tabular}

Table 3 : Conditions for free compression test on porous material conditions

The second part of the system (28) involves several isobar stages. Thus, confined compression tests were carried out at $950{ }^{\circ} \mathrm{C}$ (ie outer mold temperature) for various levels of applied pressure until complete densification was reached. The second set of experiments (see section 3.2) allowed determination of the real temperature of the powder. The relative density is computed using the displacement of the lower punch. So for each relative density, the value of $4 / c+1 / f$ can be calculated. The initial value of relative density is 0,65 . 


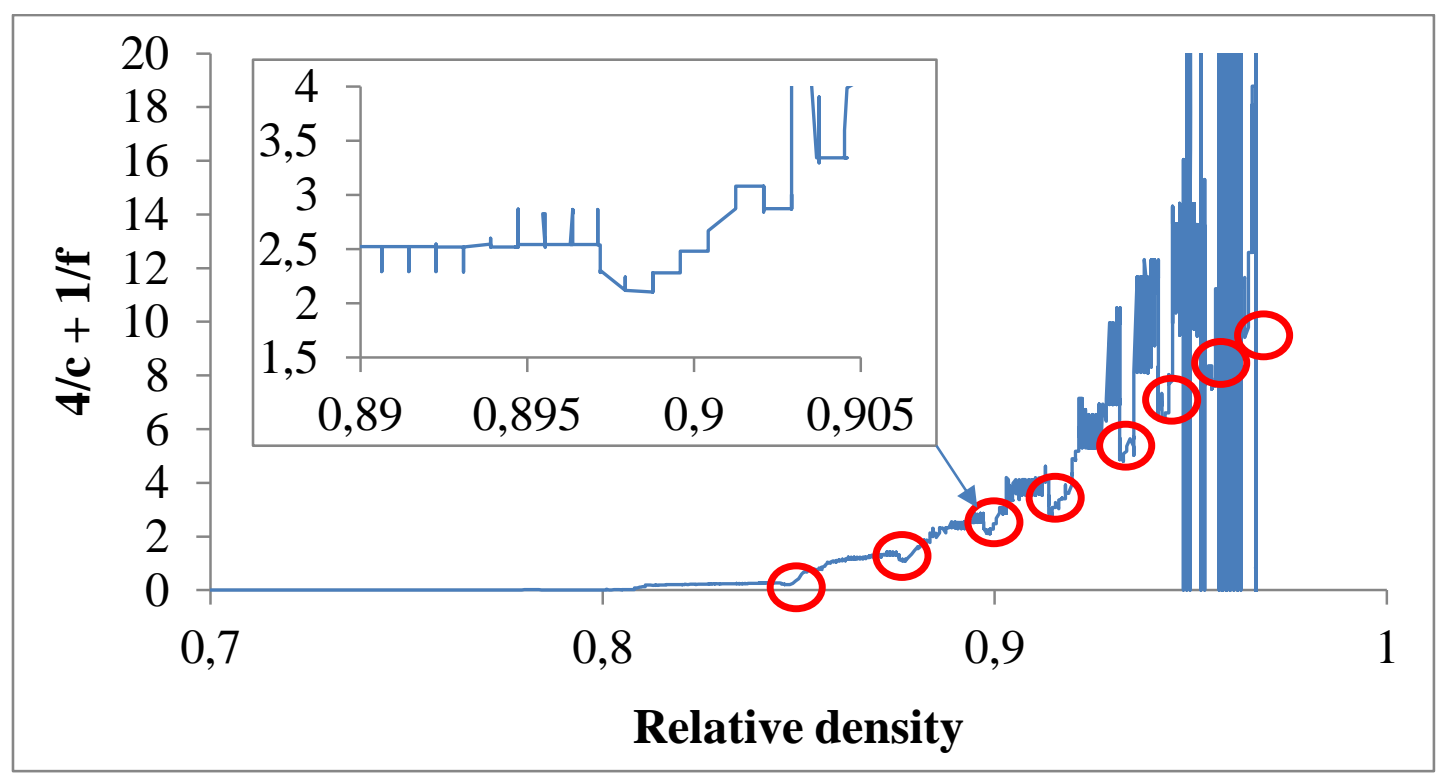

Figure $7:$ Evolution of $4 / c+1 / f$ as a function of the relative density computed with the compaction test with a zoom for $\rho_{r}=0,9$ in the box

In Figure $7,4 / c+1 / f$ values are represented during the confined compression. A lower punch displacement during application of an isobar stage implies that there has been densification.

On each of the load bearings sufficiently large for the densification to take place, three different steps are discernible. In the first step, just after the application of the load, the displacement speed of the lower piston is not constant. This therefore leads to a variation in the rate of deformation. This movement reaches a steady state, as a result of which this deformation rate is constant. Finally, the applied force is no longer large enough to generate the densification phenomenon. The value of the displacement of the lower piston decreases and tends towards 0 . Surrounded in red are located the values of $4 / c+1 / f$ computed according to the degree of porosity for the second step of each stage. Here the more the relative density values increase, the more the $4 / c+1 / f$ values increase. Under $\rho_{r}=0,85$, the value is very low due to $c$ and $f$ being very high. Only one value was found at $\rho_{r}=0,75$ equal to 0,06 .

Then, empirical expressions for $c$ and $f$ have to be used to deconvoluate both functions. The retained expressions for $c$ and $f$ functions are [6,19,26] given in (9). An optimization script was developed with Matlab ${ }^{\circledR}$ to determine the material parameters present in the equations (9). Minimizing the residual error from the least squares, the quadruple $\left(\rho_{r, c r i t}, K_{f}, \alpha, \gamma\right)$ was determined. Figure 8 presents the fit obtained between experimental values and simulated ones as well as the final shape of functions $c$ and $f$ versus relative density. 

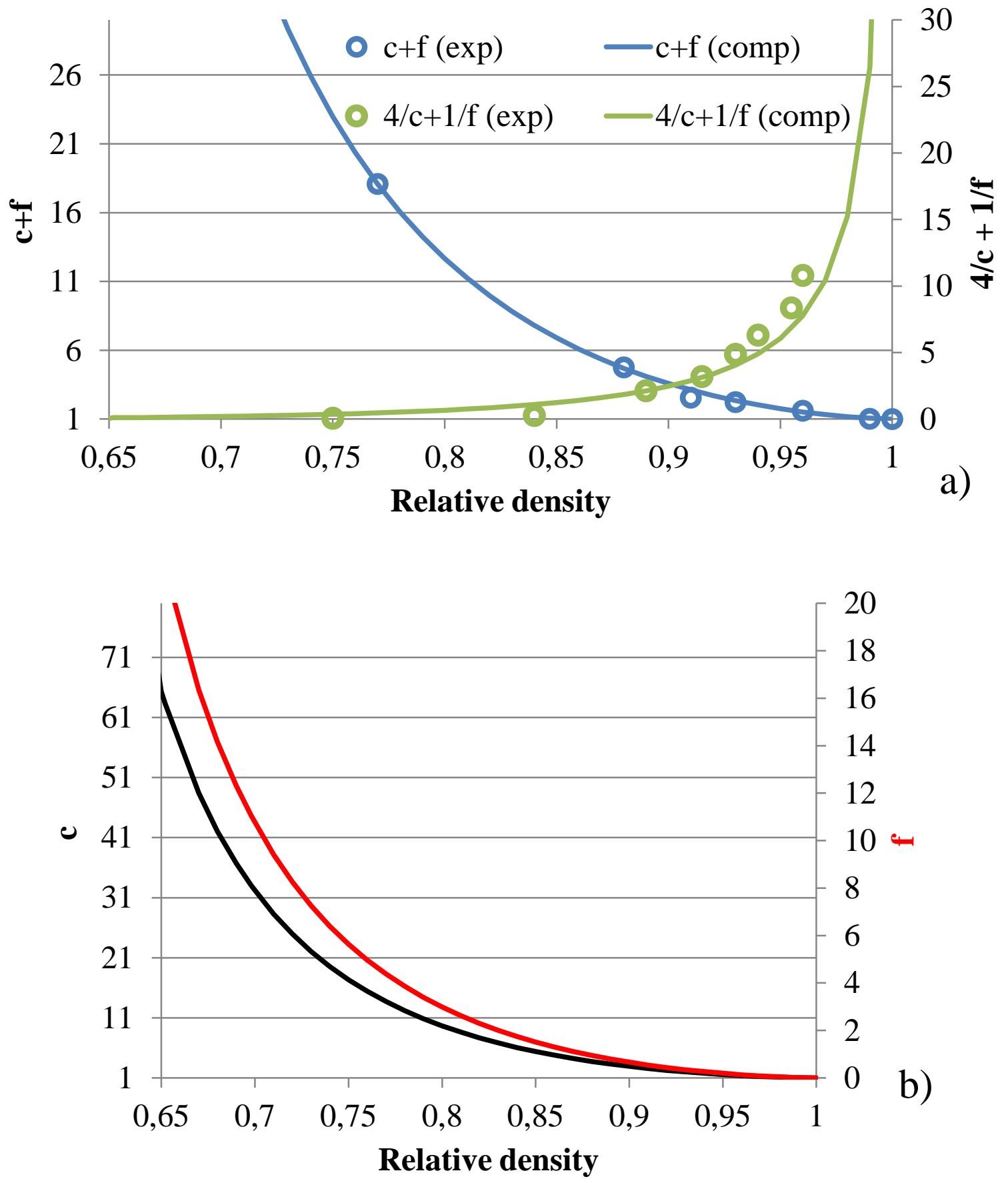

Figure 8 : Experimental (dots) and fits (lines) for $c+f(0 ;--)$ and $4 / c+1 / f(0 ;--)$ (a) and evolution of the $c, f$ functions (b) for the relative density between 0,65 and 1 .

Figure 8-a) shows that $c+f$ decreases with the relative density and tends towards 1 in the dense state. Fitted curves are in good agreement with the experimental data. Thus, it is now possible to calculate the value of the functions $c$ and $f$ for any relative density between 0,65 and 1. In the Figure 8-b, the evolutions of these two functions are presented and they both decrease when the relative density increases. 
All the parameters required to model SPS sintering of the TiAl 48-2-2 powder are summarized and reported Table 4.

\begin{tabular}{c|c|c|c} 
Parameters & $A_{0}\left(\mathrm{MPa}^{-n} \mathrm{~s}^{-1}\right)$ & $Q\left(\mathrm{~J} . \mathrm{mol}^{-1}\right)$ & $n$ \\
\hline Values & $3,1410^{8}$ & 414163 & 2,81
\end{tabular}

$$
f=4,97\left(\frac{1-\rho_{r}}{\rho_{r}-0,52}\right)^{1.51} \quad c=1+2,9 f
$$

Table 4 : Values of the creep parameters and $\boldsymbol{c}$ and $\boldsymbol{f}$ functions

\section{Numerical validation of the proposed model}

Since the creep law of TiAl 48-2-2 was determined in previous sections, the following section focuses on the validation of this model by comparing experimental and simulated sintering cycles.

A sample $8 \mathrm{~mm}$ in diameter and $10 \mathrm{~mm}$ in height was sintered by SPS at $1050{ }^{\circ} \mathrm{C}(50 \mathrm{MPa}$ and 3'). The sintering cycle resumes to a temperature ramp of $100 \mathrm{~K} / \mathrm{min}$, no dwell in temperature and a constant applied load of $50 \mathrm{MPa}$. The evolution of the relative density as function of time is given in Figure 9. Complete densification is obtained in 740 s. No densification is observed for the first $400 \mathrm{~s}$ as temperature is too low.

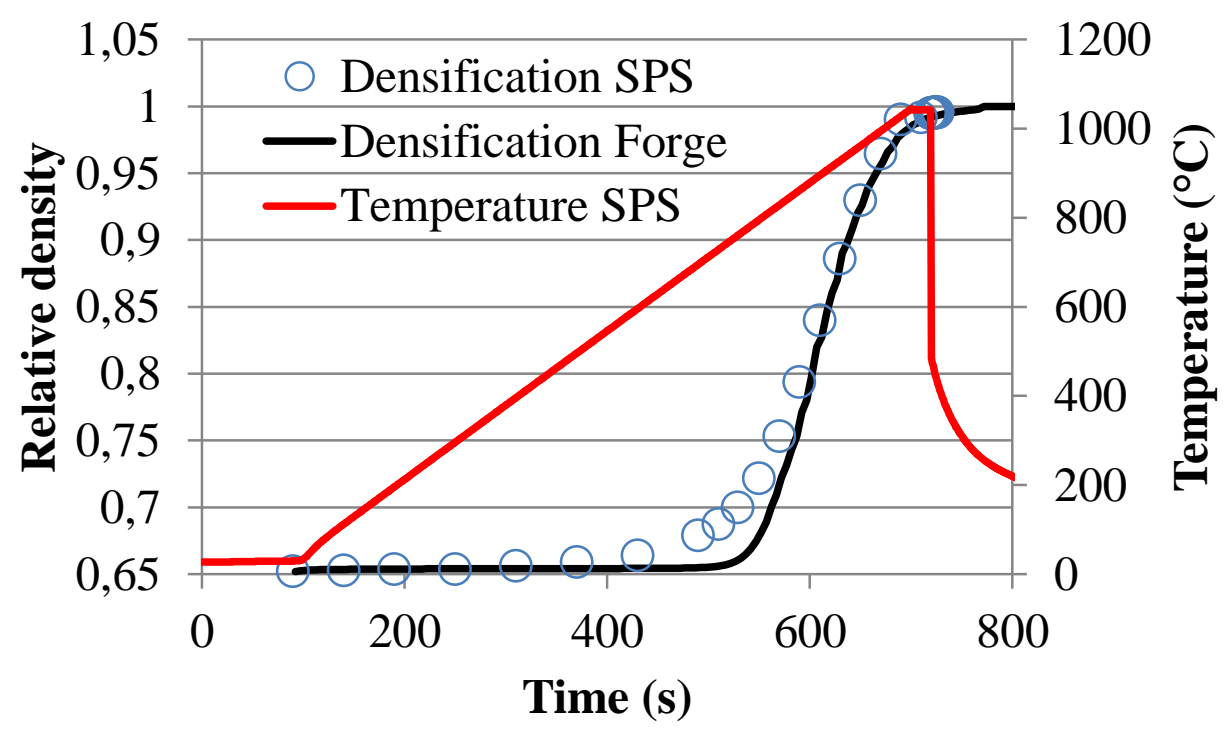

Figure 9 : Experimental and simulated densification

This densification cycle was simulated with $\mathrm{FORGE}^{\circledR}$ using the electro-thermomechanical model implemented to take into account both the Joule effect and the hot viscoplastic model written by Abouaf. The parameters $A_{0}, Q, n$, and $c, f$ functions determined previously were 
used and the simulated relative density is compared in Figure 9 with the experimental one. The correlation is very good throughout the process. The only difference is located in the early stage of densification. This difference can be explained by various phenomena. The determination of creep parameters was performed between $925^{\circ} \mathrm{C}$ and $975{ }^{\circ} \mathrm{C}$, thus creep at lower temperatures could be underestimated by the model. On the other hand, the model implemented in this study is possibly not sufficiently precise to capture the first stage of sintering, i.e. the necking phenomenon [8]. Finally, the discrepancy between experimental and simulated data could result from local plastic deformation between particles [29-30], which is not considered by the model. Further creep tests at lower temperature and interrupted tests with SEM analysis of the pores structure are needed to reach a conclusion on these points. This will be done in another study. A final comment that can be done on Figure 9 is that, despite the fact that only the mass transfer arising from the plastic deformation was considered here (as outlined in section 1), the agreement with the experimental data is excellent even at the end of the densification. This seems to indicate that for such metal densification, plastic deformation is definitely the first order phenomenon, the contribution of diffusion under load and surface tension remaining of minor importance. This will need confirmation through future extensive comparison between experimental observation and numerical solution.

\section{Conclusion}

This study focused on the protocol for the in-situ determination of the creep parameters of SPS-sintered TiAl 48-2-2 powders. This experimental protocol, associated with a proper model description of the sintering phenomenon provides acceptable and encouraging results towards the simulation of TiAl densification. This experimental methodology was developed in the framework of the Norton-Green powder compaction model, involving a relatively limited number of parameters, such as $A_{0}, Q$ and $n$ for the creep law of dense material and ( $c$, f) functions describing porous material behavior.

The unique combination of in-situ SPS creep tests on dense and porous samples as well as confined compaction experiments of powders opens a wide range of opportunities to model sintering of different kind of alloys. This potential has been demonstrated and validated on TiAl 48-2-2 case, and this approach could be generalized. 


\section{Acknowledgments}

The support of the Plateforme Nationale CNRS de Frittage Flash (PNF2/CNRS) is gratefully appreciated. D.M., F.G., P.S., K.M, M.B. and C.E. thank the French National Research Technology Association (ANRT) and Safran for financial support of this study. 


\section{Bibliography}

[1] K. Ranjit, N. Mahesh and M. Anwar, «Numerical Analysis of Powder Compaction to Obtain High Relative Density in '601AB'Aluminum Powder,» SAS Tech, vol. 11, pp. 79-84, 2012.

[2] J. Besson, PhD Thesis : Simulation numérique de la mise en forme des céramiques Application à la compaction isostatique à chaud, Ecole Nationale Supérieure MINES ParisTech, 1990.

[3] C. Manière, U. Kus, L. Durand, R. Mainguy, J. Huez, D. Delagnes and C. Estournes, «Identification of the Norton-Green compaction model for the prediction of the Ti$6 \mathrm{Al}-4 \mathrm{~V}$ densification during the Spark plasma sintering process,» Advanced Engineering Materials, vol. 18, pp. 1720-1727, 2016.

[4] C. Geindreau, D. Bouvard and P. Doremus, «Constitutive behaviour of metal powder during hot forming. Part I: Experimental investigation with lead powder as a simulation material,» Eur J Mech, vol. 18, pp. 581-596, 1999.

[5] R. Green, «A plasticity theory for porous solids,» Int J Mech Sci, vol. 14, pp. 215-224, 1972.

[6] C. Wolff, S. Mercier, H. Couque and A. Molinari, «Modeling of conventional hot compaction and Spark Plasma Sintering based on modified micromechanical models of porous materials,» Mechanics of Materials, vol. 49, pp. 72-91, 2012.

[7] D. Jarvis and D. Voss, «IMPRESS Integrated Project-An overview paper,» Mat Sci Eng, vol. 413, pp. 583-591, 2005.

[8] J. Guyon, Evolution des microstructures et mécanismes de densification d'un alliage TiAl lors du frittage par Spark Plasma Sintering, Metz: Université de Lorraine, 2015.

[9] Z. Munir, U. Anselmi-Tamburini and M. Ohyanagi, «The effect of electric field and pressure on the synthesis and consolidation of materials: a review of the spark plasma sintering method,» J Mater Sci, vol. 41, pp. 767-777, 2006.

[10] G. Molenat, L. Durand, J. Galy and A. Couret, «Temperature control in Spark Plasma sintering: an FEM approach,» Journal of Metallurgy, p. Article ID 145431, 2010.

[11] R. Orrù, R. Licheri, A. Locci, A. Cincotti and G. Cao, «Consolidation/synthesis of materials by electric current activated/assisted sintering,,» Mate Sci Eng R, vol. 63, pp. 127-287, 2009. 
[12] K. Matsugi, H. Kuramoto, T. Hatayama and O. Yanagisawa, «Temperature distribution at steady state under constant current discharge in spark sintering process of $\mathrm{Ti}$ and Al 2 O 3 powders,» J Master Process Tech, vol. 134, pp. 225-232, 2003.

[13] U. Anselmi-Tamburini, S. Gennari, J. Garay and Z. Munir, «Fundamental investigations on the spark plasma sintering/synthesis process: II. Modeling of current and temperature distributions,» Mater Sci Eng, vol. 394, pp. 139-148, 2005.

[14] A. Zavaliangos, J. Zhang, M. Kraemer and J. Groza, «Temperature evolution during field activated sintering,» Mater Sci Eng A, vol. 379, pp. 218-228, 2004.

[15] G. Maizza, S. Grasso and Y. Sakka, «Moving finite-element mesh model for aiding spark plasma sintering in current control mode of pure ultrafine WC powder,» J Mater Sci, vol. 44, pp. 1219-1236, 2009.

[16] K. Vanmeensel, A. Laptev, O. Van der Biest and J. Vleugels, «Field assisted sintering of electro-conductive ZrO 2-based composites,» J Eur Ceram Soc, vol. 27, pp. 979-985, 2007.

[17] C. Maniere, A. Pavia, L. Durand, G. Chevallier, V. Bley, K. Afanga, A. Peigney and C. Estournes, «Pulse analysis and electric contact measurements in spark plasma sintering,» Electric Power Systems Research, vol. 127, pp. 307-313, 2015.

[18] C. Maniere, A. Pavia, L. Durand, G. Chevallier, K. Afanga and C. Estournes, «Finiteelement modeling of the electro-thermal contacts in the spark plasma sintering process,» J Eur Ceram Soc, vol. 36, pp. 741-748, 2016.

[19] M. Abouaf, PhD Thesis : Modélisation de la compaction de poudres métalliques frittées Approche par la mécanique des milieux continus, Institut national Polytechnique de Grenoble, 1985.

[20] E. Olevsky, C. Garcia-Cardona, W. Bradbury, C. Haines, D. Martin and D. Kapoor, «Fundamental aspects of spark plasma sintering: II. Finite element analysis of scalability,» J Amer Ceram Soc, vol. 95, pp. 2414-2422, 2012.

[21] C. Manière, PhD Thesis : Spark Plasma Sintering : couplage entre les approches Modélisation, Instrumentation, and Matériaux, Université T3 Paul Sabatier, 2015.

[22] E. Brisson, $\mathrm{PhD}$ Thesis : Etude experimentale du frittage assemblage d'un composite conducteur en $\mathrm{Ag} \mathrm{SnO} 2$ sur un support en cuivre par courants pulsés, Université de Bretagne, 2014.

[23] X. Wei, C. Back, O. Izhvanov, O. Khasanov, C. Haines and E. Olievsky, «Spark Plasma 
Sintering of Commercial Zirconium Carbide Powders: Densification Behavior and Mechanical Properties,» Materials, vol. 8, pp. 6043-6061, 2015.

[24] E. Olevsky and L. Froyen, «Constitutive modeling of spark-plasma sintering of conductive materials,» Scripta Materialia, vol. 55, pp. 1175-1178, 2006.

[25] S. Shima and M. Oyane, «Plasticity theory for porous metals,» Int. J. Mechanical Science, vol. 18, pp. 285-291, 1976.

[26] P. Mondalek, PhD Thesis : Numerical modeling of Spark Plasma Sintering process, Ecole Nationale Supérieure MINES ParisTech, 2012.

[27] M. Abouaf, J. Chenot, G. Raisson and P. Bauduin, «Finite element simulation of hot isostatic pressing of metal powders,» Inter J Numer Meth Eng, vol. 25, pp. 191-212, 1988.

[28] C. Manière, L. Durand and C. Estournes, «Powder/die friction in the spark plasma sintering process: Modelling and experimental identification,» Scripta Materialia, vol. 116, pp. 139-142, 2016.

[29] J. Guyon, A. Hazotte, J. Monchoux and E. Bouzy, «Effect of powder state on Spark Plasma Sintering of TiAl alloys,» Intermetallics, vol. 34, pp. 94-100, 2013.

[30] H. Jabbar, A. Couret, L. Durand and J. Monchoux, «Identification of microstructural mechanisms during densification of a TiAl alloy by spark plasma sintering,» Journal of Alloys and Compounds, vol. 509, p. 9826-9835, 2011. 